\title{
Dilatometric study of phase transformations in advanced high-strength bainitic steel
}

\author{
A. Grajcar · W. Zalecki • P. Skrzypczyk • \\ A. Kilarski $\cdot$ A. Kowalski $\cdot$ S. Kołodziej
}

Received: 29 October 2013/Accepted: 27 July 2014/Published online: 4 September 2014

(c) The Author(s) 2014. This article is published with open access at Springerlink.com

\begin{abstract}
The work deals with dilatometric studies of a new-developed advanced high-strength bainitic $3 \mathrm{Mn}-1.5 \mathrm{Al}$ steel. Ferritic, bainitic and martensitic phase transformations are investigated in detail in respect of their temperature range forming and microstructures produced under various conditions of both continuous and isothermal cooling. The equilibrium temperatures of $A_{\mathrm{e} 1}$ and $A_{\mathrm{e} 3}$ and phase composition of the investigated steel were initially calculated whereas critical temperatures of $A_{\mathrm{c} 1}$ and $A_{\mathrm{c} 3}$ as well as the decomposition of retained austenite were determined upon heating. The major tests consisted of controlled cooling of undeformed or plastically deformed austenite using the dilatometer within the cooling rate range of $2-0.5^{\circ} \mathrm{C} \mathrm{s}^{-1}$. The effects of the cooling rate and deformation at temperatures of 900 and $1,050{ }^{\circ} \mathrm{C}$ on the phase transformation behaviour and microstructure were explained. The final experiment was carried out using a thermo-mechanical simulator under conditions of multistep deformation and isothermal holding of the steel at $400{ }^{\circ} \mathrm{C}$. Microstructural features were revealed using light microscopy and scanning electron microscopy techniques.
\end{abstract}

A. Grajcar $(\bowtie) \cdot$ P. Skrzypczyk · A. Kowalski · S. Kołodziej

Institute of Engineering Materials and Biomaterials, Silesian

University of Technology, 18a Konarskiego Street,

44-100 Gliwice, Poland

e-mail: adam.grajcar@polsl.pl

W. Zalecki

Institute for Ferrous Metallurgy, 12-14 K. Miarki Street, 44-100 Gliwice, Poland

\section{A. Kilarski}

General Motors, 1 Adama Opla Street, Gliwice, Poland
Keywords Dilatometric analysis - AHSS steel - Bainitic transformation $\cdot$ Multiphase microstructure $\cdot$ Retained austenite $\cdot$ Carbide-free bainite

\section{Introduction}

The beneficial combination of high strength, ductility and technological formability of steel sheets for the automotive industry can be achieved using advanced high-strength steels (AHSS). They consist of different soft and hard structural constituents in various proportions, which enable to obtain a very wide range of mechanical and technological properties. The microstructure of dual phase (DP) steel contains soft ferrite and hard martensite whereas the multiphase microstructure of TRIP (Transformation Induced Plasticity) steel consists of ferrite, bainite and retained austenite [1-6]. New demands of the automotive industry for relatively low-cost steel sheets characterized by tensile strength above 1,000 MPa require further searching of new chemical composition strategies. Advanced ultra-high-strength steels contain a higher fraction of hard phases, i.e. acicular ferrite, bainite or martensite [7-10] compared to AHSS containing polygonal ferrite as a matrix. A key microstructural constituent of advanced multiphase steels is retained austenite with the amount from 10 to $30 \%$. This phase ensures a required ductility level by its strain-induced martensitic transformation during cold forming operations. Recently, a high amount of retained austenite is obtained in different bainitic alloys containing from 1.5 up to 8 mass $\% \mathrm{Mn}$, being a main austenite stabilizer [8-14]. These steels are dedicated to the automotive industry for different crash-relevant elements, especially in the side zone of a car (B-pillars, roof rails, side-impact beams, etc.). Their wide use requires improved forming technologies and special welding procedures. 
Monitoring of phase transformations and the knowledge of continuous cooling transformation (CCT) diagrams are of primary importance for proper design of bainite-austenite microstructures with an optimal morphology. Decomposition of retained austenite on heating or cooling from the $\gamma$ region is often monitored by dilatometry, differential thermal analysis (DTA) or differential scanning calorimetry (DSC) [11, 15-17]. Results of these investigations have often to be confirmed by detailed microscopic research because phase transformations in multiphase steels are very complex. In medium-Mn steels, the bainite is particularly difficult for unequivocal identification because it can contain carbides or may form carbide-free bainite [8, 18-22]. Films of retained austenite instead of carbides occur between laths of bainitic ferrite. The destabilization of the austenite can happen during heating and cooling through precipitation of carbides, martensitic transformation, etc. Monitoring the volume fraction of all microstructural constituents and their morphology is a key to obtain optimal mechanical properties of multiphase steels. Beneficial mechanical properties and formability of steels with a bainitic-austenitic mixture are obtained for fine, homogeneous bainite microstructures. Carbide precipitates and a bimodal morphology of fine and coarse bainite are detrimental for fracture toughness and ductility of steel products [19, 20, 23].

The novelty of the present work includes the identification of temperatures of phase transformations for a newdeveloped steel containing $3 \% \mathrm{Mn}$, which was cooled from the plastically deformed recrystallized and non-recrystallized austenite regions.

\section{Experimental}

The research has been performed on newly developed $3 \mathrm{Mn}-1.5 \mathrm{Al}$ type steel with the following chemical composition: $0.17 \% \mathrm{C}, 3.3 \% \mathrm{Mn}, 1.7 \% \mathrm{Al}, 0.22 \% \mathrm{Si}$, $0.23 \% \mathrm{Mo}, 0.014 \% \mathrm{~S}$ and $0.01 \% \mathrm{P}$. Increased concentration of $\mathrm{Mn}$ is to stabilize retained austenite and addition of $\mathrm{Al}$ prevents precipitation of carbides during a bainitic transformation, favouring formation of carbide-free bainite $[8,9,18]$. A 25-kg ingot was produced by vacuum induction melting in the Balzers VSG-50 furnace. Basic charge consisted of Armco iron and alloying additions in the form of pure elements $(\mathrm{C}, \mathrm{Si}, \mathrm{Mn}, \mathrm{Mo}, \mathrm{Al})$. Iron and molybdenum were loaded into the crucible, while the alloying additions were distributed into individual compartments of the alloy hopper, in the sequence complying with their subsequent introduction into the bath (Al, Si, $\mathrm{Mn}, \mathrm{C}$ ). Liquid metal was cast under Ar atmosphere from the temperature of $1545{ }^{\circ} \mathrm{C}$ into a hot-topped closed-bottom wide-end-up cast iron mould with internal dimensions: bottom- $\varnothing 122 \mathrm{~mm}$, top- $\varnothing 145 \mathrm{~mm}$, height-200 mm. The ingot was subjected to forging at a temperature range from 1,200 to $900{ }^{\circ} \mathrm{C}$ to a thickness of $22 \mathrm{~mm}$. Then, tubular samples, $\varnothing 4 \times \varnothing 3 \times 7 \mathrm{~mm}$, and $\varnothing 3 \times 7 \mathrm{~mm}$ cylindrical specimens for dilatometric investigations were machined. Finally, the $\varnothing 10 \times 12 \mathrm{~mm}$ specimens were prepared for multi-step hot compression tests.

Dilatometric analyses were conducted with the use of DIL805 dilatometer produced by Bähr Thermoanalyse $\mathrm{GmbH}$, equipped with LVDT type measuring head with theoretical resolution of $\pm 0.057 \mu \mathrm{m}$. Investigation and analysis of dilatograms and determination of critical temperatures were made according to recommendations of Standard Practice issued by ASTM International [24] using the technique of applying the tangent to the dilatation curve near the beginning and the end of phase transition. In case of inseparable transformations (occurring one after another), numerical differentiation of dilatation curves was used for the analysis. In case of examination of ferritic transformation, the method based on linear transformation of analysed section of dilatation curve was applied in order to determine the start and finish temperature of phase transition.

The non-deformed specimens were exposed to heat setting [24], i.e. heated up to the temperature of $650{ }^{\circ} \mathrm{C}$ with a rate of $10{ }^{\circ} \mathrm{C} \mathrm{s}^{-1}$ and successively held for $10 \mathrm{~min}$, then cooled down with a rate of $30{ }^{\circ} \mathrm{C} \min ^{-1}$ to ambient temperature (Fig. 1). This step is required by the standard to eliminate any internal stresses caused during manufacturing and sample's preparing. The main study involved conducting three types of experiment:

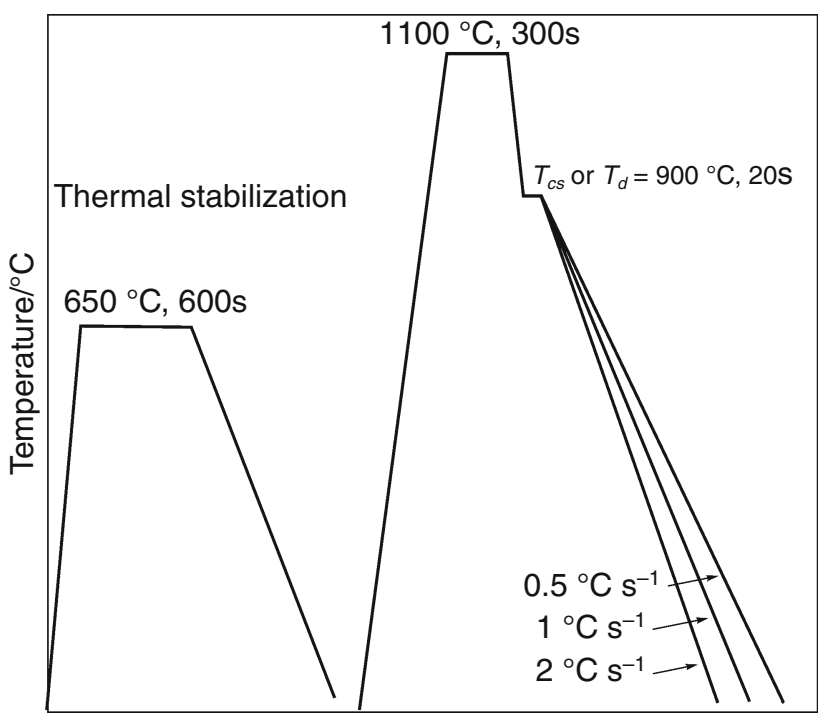

Time/s

Fig. 1 Schematic of thermal treatment schedules applied for dilatometric samples 
- heating tubular samples with a rate of $3{ }^{\circ} \mathrm{C} \mathrm{s}^{-1}$ up to the temperature of $1,100{ }^{\circ} \mathrm{C}$, their austenitizing for $300 \mathrm{~s}$, cooling with a rate of $5{ }^{\circ} \mathrm{C} \mathrm{s}^{-1}$ to the temperature of $900{ }^{\circ} \mathrm{C}$, isothermal holding for $20 \mathrm{~s}$ and final cooling at a rate of 2,1 and $0.5^{\circ} \mathrm{C} \mathrm{s}^{-1}$ to room temperature (Fig. 1);

- heating cylindrical samples with a rate of $3{ }^{\circ} \mathrm{C} \mathrm{s}^{-1}$ up to the temperature of $1,100{ }^{\circ} \mathrm{C}$, their austenitizing for $300 \mathrm{~s}$, cooling with a rate of $5{ }^{\circ} \mathrm{C} \mathrm{s}^{-1}$ to the temperature of $900{ }^{\circ} \mathrm{C}$. The samples were isothermally held within $20 \mathrm{~s}$ and compressed applying the logarithmic strain of 0.5 with a stain rate of $1 \mathrm{~s}^{-1}$. Final cooling to room temperature was carried out at a rate of 2, 1 and $0.5{ }^{\circ} \mathrm{C} \mathrm{s}^{-1}$; and

- heating cylindrical samples with a rate of $3^{\circ} \mathrm{C} \mathrm{s}^{-1}$ up to the temperature of $1,100{ }^{\circ} \mathrm{C}$, their austenitizing for $300 \mathrm{~s}$, cooling with a rate of $5{ }^{\circ} \mathrm{C} \mathrm{s}^{-1}$ to the temperature of $1,050^{\circ} \mathrm{C}$. The samples were isothermally held within $20 \mathrm{~s}$ and compressed applying the logarithmic strain of 0.5 with a stain rate of $1 \mathrm{~s}^{-1}$. Final cooling to room temperature was carried out at a rate of 2,1 and $0.5{ }^{\circ} \mathrm{C} \mathrm{s}^{-1}$.

Various deformation of samples at the temperature of 900 and $1,050{ }^{\circ} \mathrm{C}$ was to determine the effect of austenite state (non-recrystallized and recrystallized) on temperatures of phase transformations during cooling, as well as its impact on steel microstructure. A final experiment was carried out using the "Hydrawedge" unit of Gleeble 3800 simulator to reflect a thermo-mechanical path applied for TRIP steel sheets. The test consisted of four-step compression at temperatures of $1,150,1,050,950$ and $850{ }^{\circ} \mathrm{C}$ followed by multi-step controlled cooling to room temperature. After the final deformation, the specimens were rapidly cooled to $700{ }^{\circ} \mathrm{C}$ and next slowly for $50 \mathrm{~s}$ within the temperature range of $700-650{ }^{\circ} \mathrm{C}$. Then, the samples were cooled at the rate of $40{ }^{\circ} \mathrm{C} \mathrm{s}^{-1}$ to $400{ }^{\circ} \mathrm{C}$ and isothermally held for $300 \mathrm{~s}$. Finally, the deformed specimens were cooled with a rate of $0.5^{\circ} \mathrm{C} \mathrm{s}^{-1}$ to room temperature.

Microstructure of steel in the initial state, after dilatometric analyses and after thermo-mechanical processing, was examined with the use of light microscopy (LM) and scanning electron microscopy (SEM). The specimens after dilatometric investigations were etched in $5 \%$ nital, while after thermo-mechanical treatment they were etched in $10 \%$ aqueous solution of sodium metabisulfite. Microstructure observations were carried out with the Leica MEF 4A light microscope. Morphological details of microstructural constituents were revealed with the SUPRA 25 scanning electron microscope at the accelerating voltage of $20 \mathrm{kV}$.

$\mathrm{X}$-ray examination was carried out with filtered Co radiation and an X-pert PRO diffractometer operating at
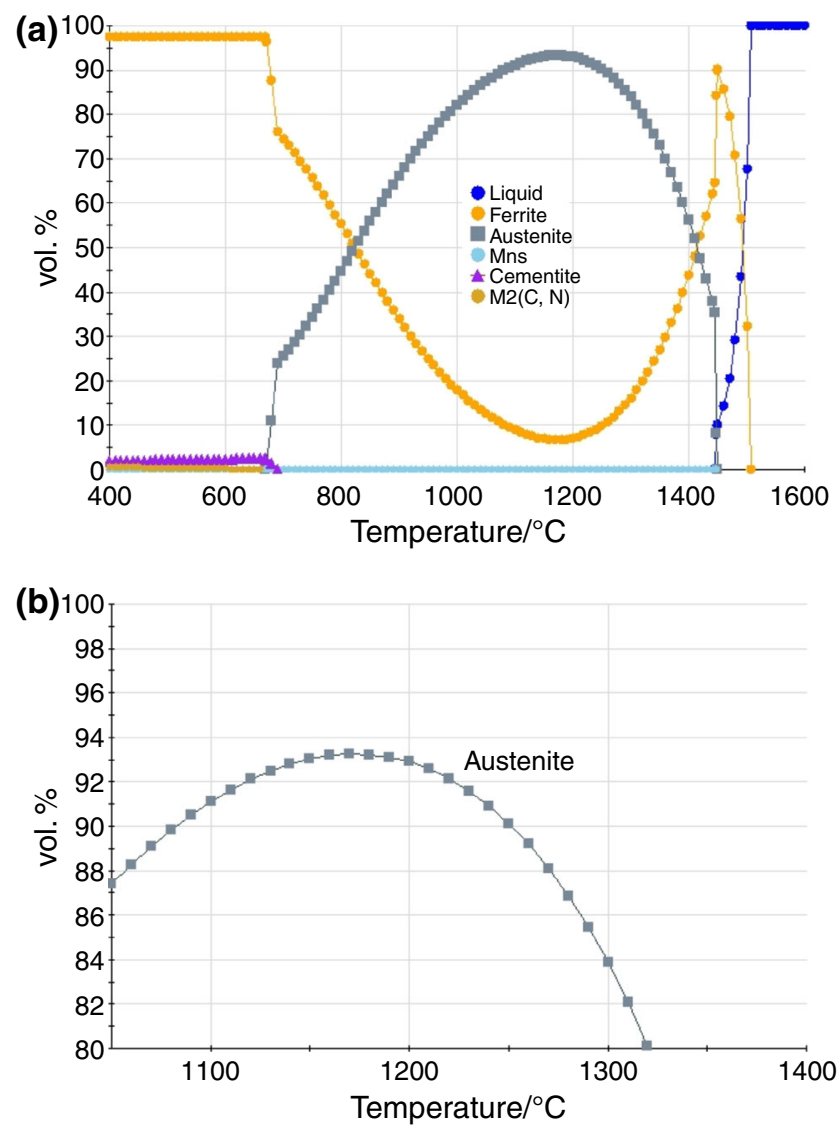

Fig. 2 Thermodynamic equilibrium diagrams determined using the JMatPro software (a), a part of the diagram showing the austenite fraction as a function of temperature (b)

$40 \mathrm{kV}$ and $30 \mathrm{~mA}$, equipped with an $\mathrm{X}^{\prime}$ Celerator detector. Three alpha and four gamma peaks were quantified by scanning through a 2-theta range from 40 to $115 \mathrm{deg}$. To minimize the effect of texture, the amount of retained austenite was quantified on the basis of the integrated intensity of three pairs of diffraction lines using the Averbach-Cohen approach.

\section{Results and discussion}

Thermodynamic equilibrium diagrams

The first stage of the study was calculating the change of volume fractions of individual phases as a function of temperature. Calculations were performed with the use of JMatPro programme under conditions of thermodynamic equilibrium [25]. The calculation results are shown in Fig. 2. Determined solidus temperature is equal to $1,445{ }^{\circ} \mathrm{C}$, and liquidus temperature is equal to $1,507{ }^{\circ} \mathrm{C}$. The equilibrium temperature of $\alpha$ phase transformation $A_{\mathrm{e} 1}$ into austenite is equal to $669{ }^{\circ} \mathrm{C}$. Area of austenitic phase is 


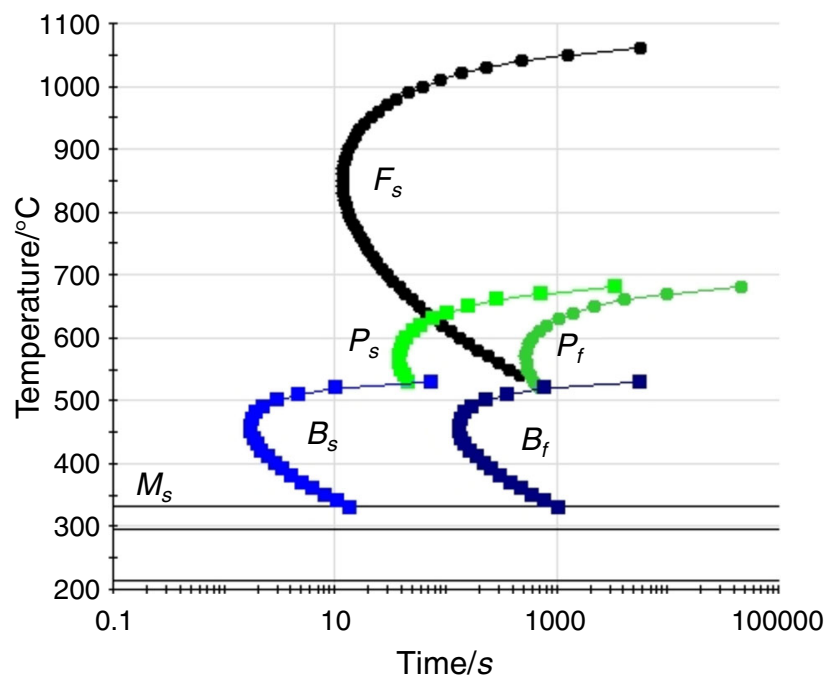

Fig. 3 Time-temperature-transformation (TTT) diagram of the steel austenitized at $1,100{ }^{\circ} \mathrm{C}$ calculated using the JMatPro software

in a temperature range from 669 to $1,445{ }^{\circ} \mathrm{C}$. The decrease of temperature results in the precipitation of $\delta$ ferrite from liquid, which successively undergoes allotropic transformation into austenite (Fig. 2a). The amount of $\gamma$ phase initially increases and then decreases. The maximum volume fraction of austenite is $93.2 \%$, what takes place at a temperature of $1,170{ }^{\circ} \mathrm{C}$ (Fig. 2b). The lack of one-phase area of $\gamma$ phase is mainly due to increased concentration of Al up to $1.7 \%$, which is a strong ferrite-forming element. The calculated amount of austenite is equal to $91.1 \%$ when analysing the austenitizing temperature of $1,100{ }^{\circ} \mathrm{C}$. Cementite and $\mathrm{M}_{2}(\mathrm{C}, \mathrm{N})$-type carbides can be also present under equilibrium conditions at room temperature.

Figure 3 shows the time-temperature-transformation (TTT) diagram of the steel austenitized at $1,100{ }^{\circ} \mathrm{C}$ calculated using the JMatPro software. It can be seen that the ferritic transformation start temperature $\left(F_{\mathrm{s}}\right)$ is very high and it is equal to $1076{ }^{\circ} \mathrm{C}$. This behaviour is due to a high $\mathrm{Al}$ content in the steel. The martensite start temperature $\left(M_{\mathrm{s}}\right)$ is relatively low, what favours austenite stabilization in TRIP steels [1-3]. Pearlite is delayed to long times and the bainitic field is left-shifted. The real CCT diagram included elsewhere [9] indicates that a ferrite fraction is very low and a pearlitic transformation is efficiently avoided up to $1,000 \mathrm{~s}$. These conditions are very desired in respect of the thermal stabilization of retained austenite.

Microstructure of steel in the initial state, i.e. after hot forging and air cooling is presented in Fig. 4. There are visible grain boundaries of prior austenite with the size of 20-30 $\mu \mathrm{m}$. The fraction of polygonal ferrite in the form of fine grains is negligibly small. It means that the steel exhibits increased hardenability-mainly due to increased concentration of $\mathrm{Mn}$ and Mo. Under these conditions,
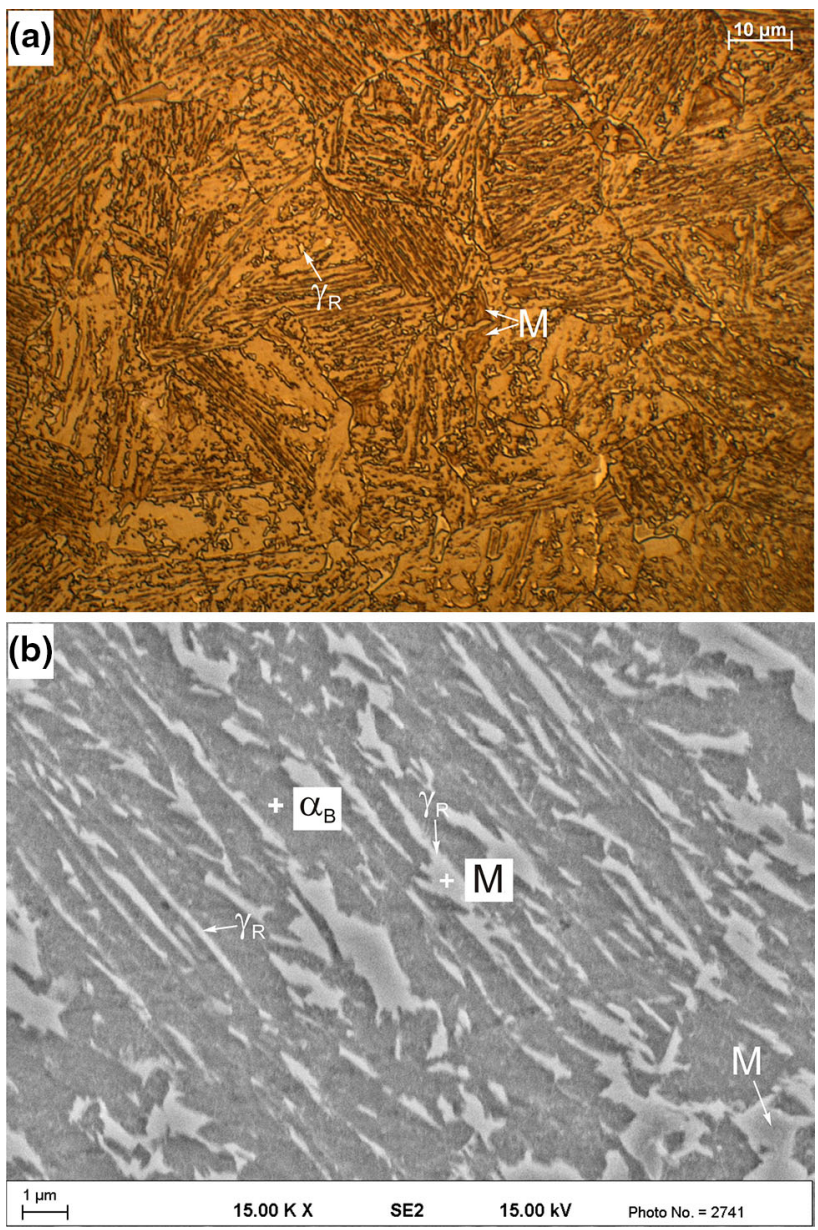

Fig. 4 Bainitic microstructure containing retained austenite and martensite of the steel at the initial state (a), retained austenite located between bainitic ferrite laths $(\mathbf{b}) ; \alpha_{B}$ bainitic ferrite, $\gamma_{R}$ retained austenite, $M$ martensite

bainite is a dominant structural component. Fine, bright grains with a size of approximately $1 \mu \mathrm{m}$ are retained austenite (Fig. 4a), which means that high concentration of $\mathrm{Al}$ and $0.2 \%$ of $\mathrm{Si}$ prevents precipitation of carbides in bainite even without the use of isothermal stop in the bainitic range. Aluminium and silicon are graphitizing elements showing an extremely low solubility in cementite. They form a buildup around a carbide nucleus and hence they increase considerably the carbon activity locally preventing its diffusion to the potential nucleus [26]. This mechanism is especially efficient during the isothermal bainitic step. The presence of retained austenite is also confirmed by the SEM microstructure, where thin laths of $\gamma$ phase are visible between laths of bainitic ferrite (Fig. 4b). The largest grains of $\gamma$ phase are usually located at the boundaries of individual sheaves of bainite and undergo martensitic transformation due to their higher $M_{\mathrm{s}}$ temperature $[9,19]$. The occurrence of retained austenite is also confirmed by X-ray examination. The XRD results given in 
Table 1 Fraction of retained austenite determined by X-ray diffraction

\begin{tabular}{lll}
\hline & $\begin{array}{l}\text { Initial } \\
\text { state }\end{array}$ & $\begin{array}{l}\text { Thermo-mechanical } \\
\text { processing }\end{array}$ \\
\hline $\begin{array}{l}\text { Retained austenite } \\
\text { fraction/\% }\end{array}$ & $11.1 \pm 1.2$ & $17.5 \pm 1.6$ \\
\hline
\end{tabular}

Table 1 indicate that the amount of $\gamma$ phase in the initial state is equal to about $11 \%$. It is in good agreement with microstructural results (Fig. 4).

Determination of critical temperatures

Critical $A_{\mathrm{c} 1}$ and $A_{\mathrm{c} 3}$ temperatures were determined at a heating rate of $0.042{ }^{\circ} \mathrm{C} \mathrm{s}^{-1}$. The $A_{\mathrm{c} 3}$ temperature has not been reached. The successive metallographic studies revealed the presence of non-transformed ferrite, what is consistent with the results of dilatometric analyses and thermodynamic calculations. The $A_{\mathrm{c} 1}$ temperature of steel is equal to $695{ }^{\circ} \mathrm{C}$. This confirms the dependence that under real heating conditions, the $A_{\mathrm{c} 1}$ temperature is higher than $A_{\mathrm{e} 1}$ equilibrium temperature. For accepted heating rate, the $A_{\mathrm{c} 1}$ temperature is higher than equilibrium temperature by $26{ }^{\circ} \mathrm{C}$. For a heating rate applied $\left(0.042{ }^{\circ} \mathrm{C} \mathrm{s}^{-1}\right)$, confidential limits do not exceed $\pm 3{ }^{\circ} \mathrm{C}$ for the $A_{\mathrm{c} 1}$ temperature.

Determination of $A_{\mathrm{c} 1}$ temperature was not easy, as the first deviation on dilatograms of heating has already occurred at the temperature of $631{ }^{\circ} \mathrm{C}$. Analysis of dilatograms registered in the process of heat setting appeared to be useful in this case. Figure 5 presents a part of the dilatogram during isothermal holding of sample at $650{ }^{\circ} \mathrm{C}$. Increase of volume occurs during annealing, and therefore this cannot be $\alpha \rightarrow \gamma$ transformation, which should be accompanied by a volume decrease [22, 23, 27]. Taking into consideration the presence of retained austenite in the initial microstructure (Fig. 4), it should be expected that decomposition of $\gamma$ phase occurs during heating of steel. This phenomenon in bainitic steels containing retained austenite was studied by Yang and Bhadeshia [17]. They found that decomposition of austenite into the mixture of ferrite and carbides is accompanied by expansion of the specimen, visible on dilatometric curve on heating. In turn, Caballero et al. [22] observed that the volume change depends on the content of $\mathrm{C}$ in retained austenite. They have stated that contraction of the specimen in $0.8 \mathrm{C}-2 \mathrm{Mn}-$ $1.6 \mathrm{Si}-1.3 \mathrm{Cr}-0.3 \mathrm{Mo}$ steel occurs at carbon concentration above $1.5 \%$. Such high content of $\mathrm{C}$ in austenite is not possible in the present study, taking into account that its concentration in examined steel is equal to $0.17 \%$. The expansion in the dilatometric isothermal holding curve (Fig. 5) should be connected with precipitation of carbides

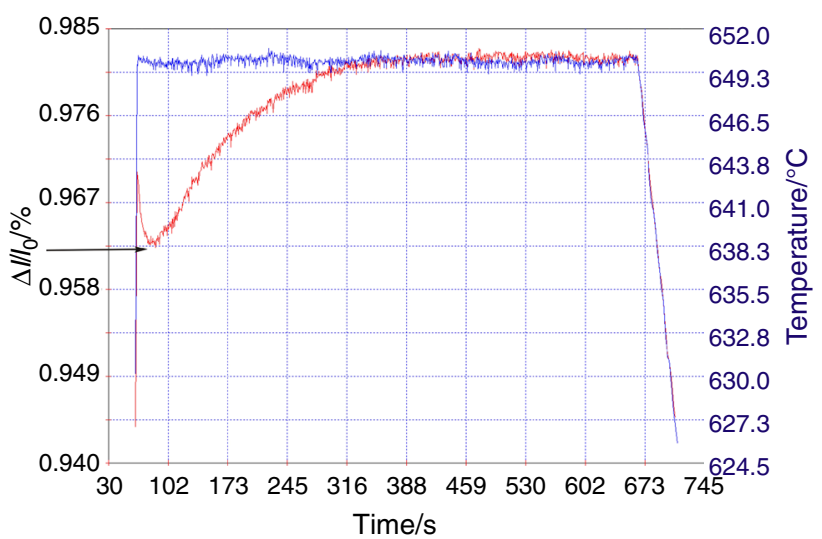

Fig. 5 Dilatometric curve registered at $650{ }^{\circ} \mathrm{C}$ during isothermal holding of steel

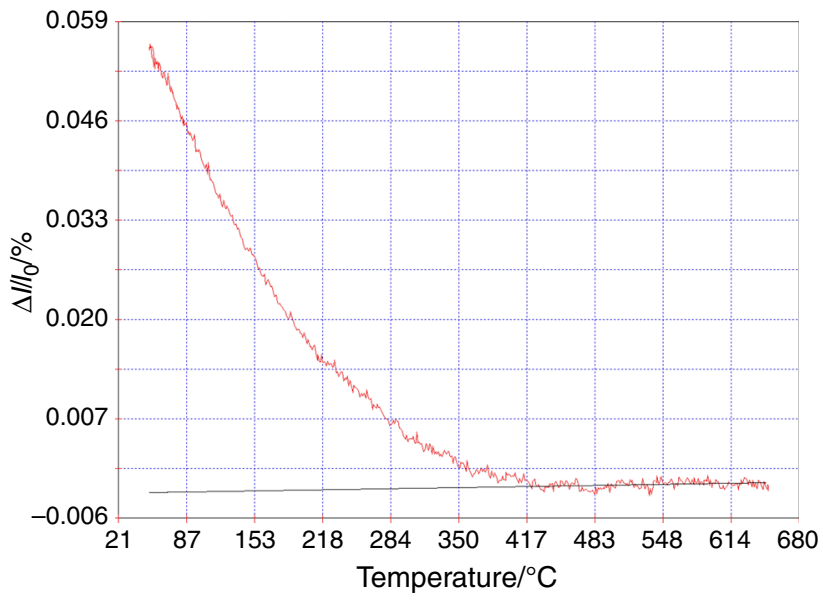

Fig. 6 Dilatometric curve registered during cooling after the thermal stabilization of steel at $650{ }^{\circ} \mathrm{C}$

from $\gamma$ phase, which is confirmed by previous findings of other authors [17, 22]. During successive cooling, the volume expansion of the sample occurs from the temperature of $416{ }^{\circ} \mathrm{C}$ (Fig. 6). This confirms an earlier argument about precipitation of carbides and the accompanying decrease of $\gamma$ phase stability, leading to martensitic transformation of remaining austenite fraction, which was not previously destabilized into the mixture of ferrite and carbides.

Effect of deformation conditions on dilatometric response

Example dilatogram for a non-deformed sample cooled at a rate of $2{ }^{\circ} \mathrm{C} \mathrm{s}^{-1}$ from the temperature of $900{ }^{\circ} \mathrm{C}$ is presented in Fig. 7. For a correct analysis of dilatometric 


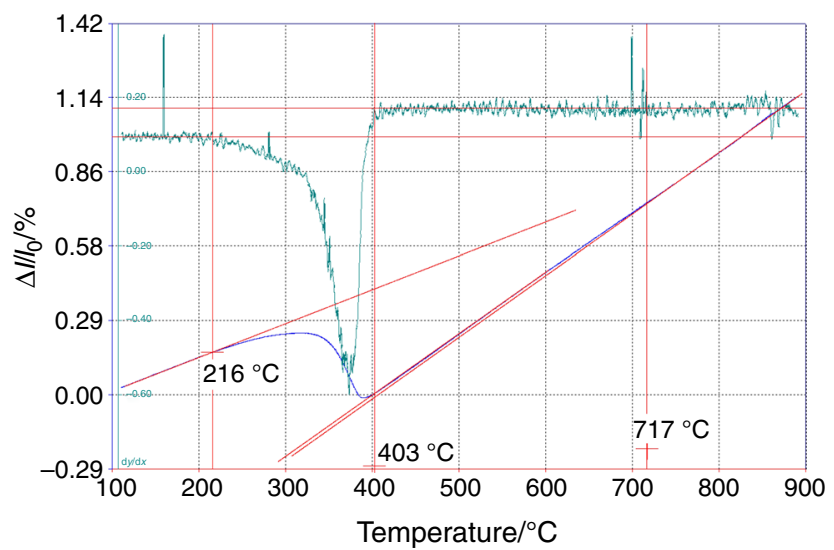

Fig. 7 Cooling dilatometric curve and its differential curve corresponding to a cooling rate of $2{ }^{\circ} \mathrm{C} \mathrm{s}^{-1}$ for undeformed steel
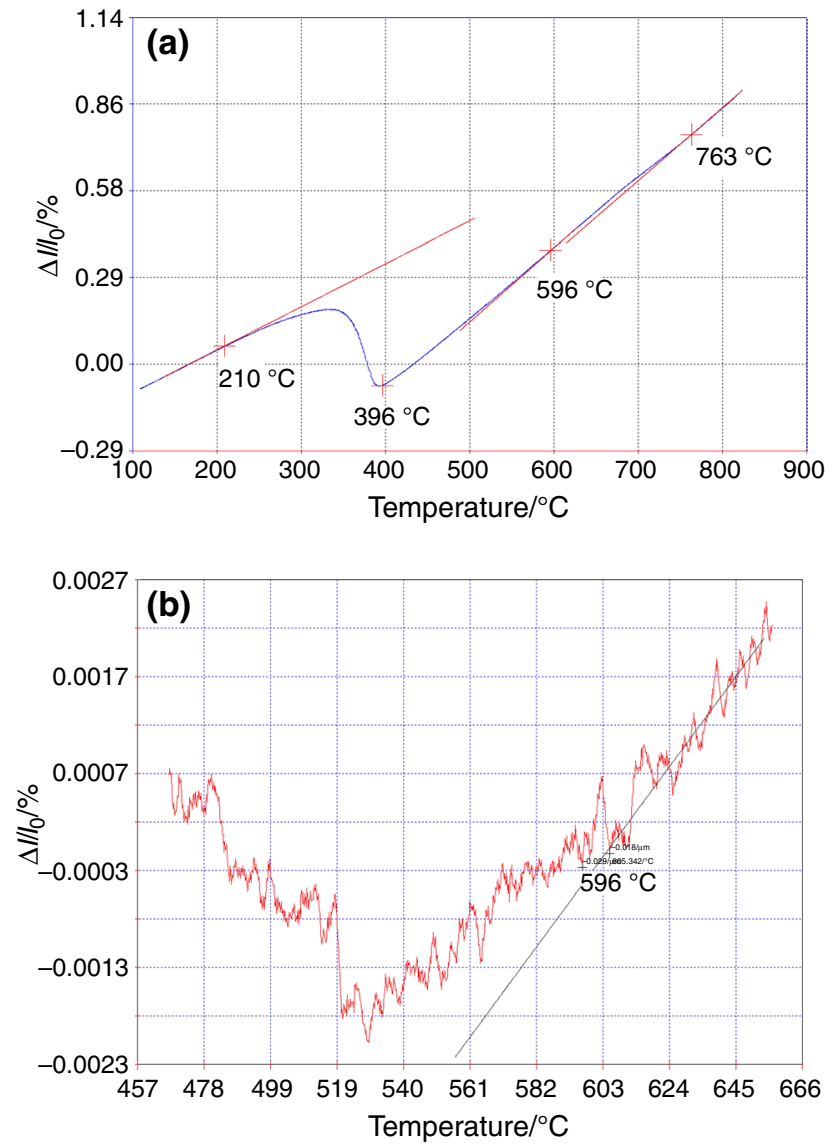

Fig. 8 Cooling dilatometric curve (a) and a part of its differential curve within the temperature range of bainitic transformation (b) corresponding to a cooling rate of $1{ }^{\circ} \mathrm{C} \mathrm{s}^{-1}$ for undeformed steel

curve, it was necessary to use a differential curve. The amount of austenite transformed into ferrite and bainite is very small, what represents only a slight deviation in the dilatometric curve. Distinct increase in sample length occurs during transformation of $\gamma$ phase into martensite,

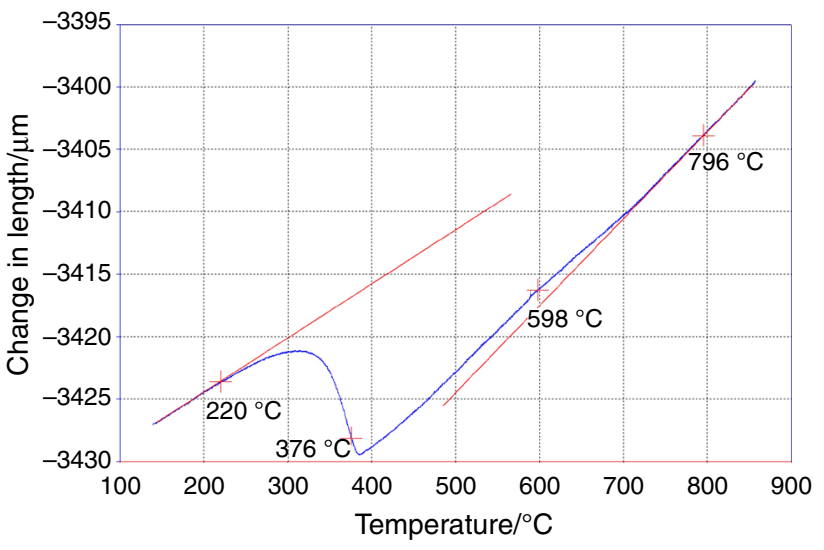

Fig. 9 Cooling dilatometric curve corresponding to a cooling rate of $1{ }^{\circ} \mathrm{C} \mathrm{s}^{-1}$, for steel deformed at $1,050{ }^{\circ} \mathrm{C}$

which happens in a temperature range from 403 to $216{ }^{\circ} \mathrm{C}$. In the similar temperature range also martensitic transformation took place in case of a specimen cooled after stabilization (Fig. 6). Confidential limits for the $M_{s}$ temperature are $\pm 2{ }^{\circ} \mathrm{C}$ within cooling rates between 550 and $0.5^{\circ} \mathrm{C} \mathrm{s}^{-1}$.

Dilatograms registered at a lower cooling rate are very similar. In case of the sample cooled at a rate of $1{ }^{\circ} \mathrm{C} \mathrm{s}^{-1}$, first deviation of tangent from the dilatometric curveequivalent to the start of ferritic transformation-occurs at $763{ }^{\circ} \mathrm{C}$ (Fig. 8a). However, the amount of this structural constituent is minimal, similar as per bainite. The differential curve shown in Fig. $8 \mathrm{~b}$ reveals that the temperature of the beginning of bainitic transformation is equal approximately to $596{ }^{\circ} \mathrm{C}$. The range of martensitic transformation is similar as for the cooling rate of $2{ }^{\circ} \mathrm{C} \mathrm{s}^{-1}$.

Plastic deformation of steel at the temperature of $1,050{ }^{\circ} \mathrm{C}$ has a moderate impact on the shape of a dilatogram presented in Fig. 9, for the sample cooled at a rate of $1{ }^{\circ} \mathrm{C} \mathrm{s}^{-1}$. Again, the volume fractions of ferrite and bainite are minor, and considerable increase of volume is registered in a temperature range corresponding to martensitic transformation. Comparing non-deformed and deformed samples, a certain increase of ferritic transformation start temperature $\left(F_{\mathrm{s}}\right)$ can be observed. The temperature increase is the highest for a cooling rate of $2{ }^{\circ} \mathrm{C} \mathrm{s}^{-1}$ and it reaches $68{ }^{\circ} \mathrm{C}$. The growth of the ferritic transformation start temperature is smaller with decreasing the cooling rate to 1 and $0.5^{\circ} \mathrm{C} \mathrm{s}^{-1}$ (Table 2). Additionally, plastic deformation results in the decrease of the martensitic transformation range by about $20^{\circ} \mathrm{C}$. Larger amount of ferrite and bainite can be expected only after decreasing the cooling rate of steel to $0.1^{\circ} \mathrm{C} \mathrm{s}^{-1}$, which indicates larger deviation of dilatation curve from respective tangents (Fig. 10). Under such conditions, temperature ranges of all phase transformations were significantly shifted up, i.e. to higher temperatures. 
Table 2 Comparison of start and finish temperatures of phase transformation within the cooling rate range between 2 and $0.5^{\circ} \mathrm{C} \mathrm{s}^{-1}$

\begin{tabular}{|c|c|c|c|c|}
\hline \multirow[t]{2}{*}{ Def. temp. $/{ }^{\circ} \mathrm{C}$} & \multirow[t]{2}{*}{ Trans. type } & \multicolumn{3}{|c|}{ Cooling rate $/{ }^{\circ} \mathrm{C} \mathrm{s}{ }^{-1}$} \\
\hline & & 2 & 1 & 0.5 \\
\hline \multirow[t]{6}{*}{-} & $F_{\mathrm{s}}$ & 717 & 763 & 775 \\
\hline & $F_{\mathrm{f}}$ & 593 & 625 & 648 \\
\hline & $B_{\mathrm{s}}$ & 593 & 596 & 594 \\
\hline & $B_{\mathrm{f}}$ & 403 & 396 & 399 \\
\hline & $M_{\mathrm{s}}$ & 403 & 396 & 399 \\
\hline & $M_{\mathrm{f}}$ & 216 & 210 & 224 \\
\hline \multirow[t]{6}{*}{1,050} & $F_{\mathrm{s}}$ & 785 & 796 & 792 \\
\hline & $F_{\mathrm{f}}$ & 595 & 598 & 601 \\
\hline & $B_{\mathrm{s}}$ & 595 & 598 & 601 \\
\hline & $B_{\mathrm{f}}$ & 380 & 376 & 376 \\
\hline & $M_{\mathrm{s}}$ & 380 & 376 & 376 \\
\hline & $M_{\mathrm{f}}$ & 212 & 220 & 232 \\
\hline \multirow[t]{6}{*}{900} & $F_{\mathrm{s}}$ & 774 & 791 & 810 \\
\hline & $F_{\mathrm{f}}$ & 594 & 591 & 594 \\
\hline & $B_{\mathrm{s}}$ & 594 & 591 & 594 \\
\hline & $B_{\mathrm{f}}$ & 368 & 372 & 372 \\
\hline & $M_{\mathrm{s}}$ & 368 & 372 & 372 \\
\hline & $M_{\mathrm{f}}$ & 216 & 212 & 237 \\
\hline
\end{tabular}

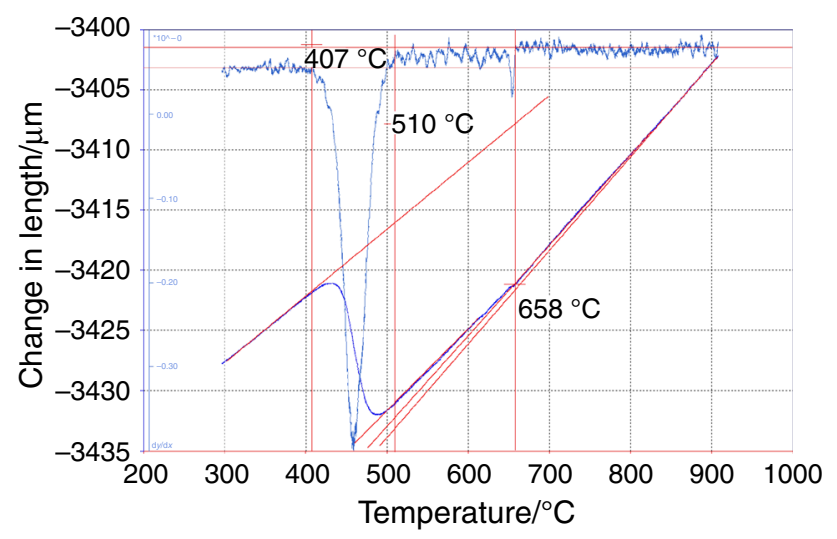

Fig. 10 Cooling dilatometric curve and its differential curve corresponding to a cooling rate of $0.1{ }^{\circ} \mathrm{C} \mathrm{s}^{-1}$, for steel deformed at $1,050{ }^{\circ} \mathrm{C}$

For samples deformed at $900{ }^{\circ} \mathrm{C}$, temperatures of individual phase transitions are similar to the temperatures registered on dilatograms during cooling of samples subjected to recrystallization at the temperature of $1,050{ }^{\circ} \mathrm{C}$. As per example, for a cooling rate of $1{ }^{\circ} \mathrm{C} \mathrm{s}^{-1}$, the temperatures are equal to $F_{\mathrm{s}}=791{ }^{\circ} \mathrm{C}, B_{\mathrm{s}}=591{ }^{\circ} \mathrm{C}$ and $M_{\mathrm{s}}=372{ }^{\circ} \mathrm{C}$ (Fig. 11). Summary of start and finish temperatures for individual phase transformations registered on dilatograms is presented in Table 2. The temperature ranges of phase transformations for samples deformed under

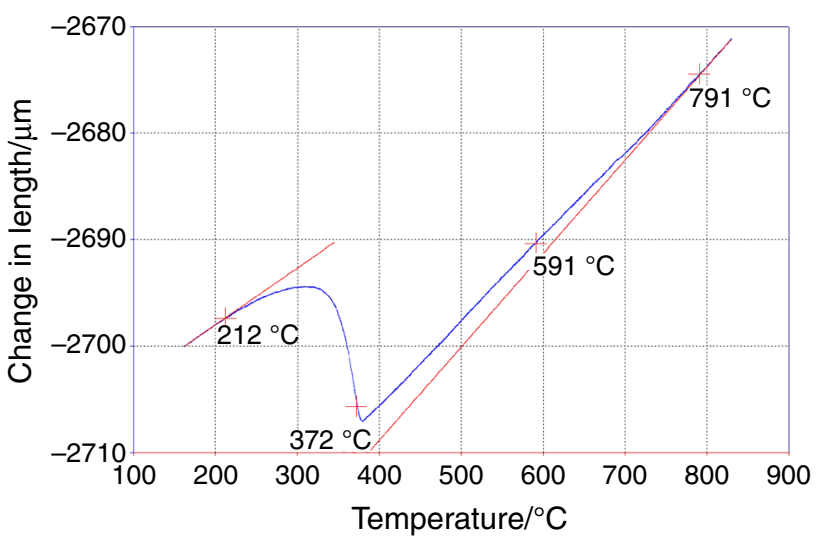

Fig. 11 Cooling dilatometric curve corresponding to a cooling rate of $1{ }^{\circ} \mathrm{C} \mathrm{s}^{-1}$, for steel deformed at $900{ }^{\circ} \mathrm{C}$

conditions of recrystallization and its absence are similar. Increase of transformation start temperature of austenite into ferrite and decrease of temperature range of diffusionless transformation can be observed when compared to non-deformed specimens. This is due to the fact that lattice defects caused by plastic deformation are privileged areas for ferrite nucleation. On the other hand, dislocations and other lattice imperfections inhibit the growth of martensite lamellas.

Effects of deformation and cooling conditions on microstructure

Conditions of plastic deformation and cooling essentially influence microstructure of steel. Figure 12 presents microstructures of specimens cooled from $900{ }^{\circ} \mathrm{C}$ without deformation (Fig. 12a, d, g), after deformation under conditions of austenite recrystallization at $1,050{ }^{\circ} \mathrm{C}$ (Fig. 12b, $\mathrm{e}, \mathrm{h})$ and its absence at the temperature of $900{ }^{\circ} \mathrm{C}$ (Fig. 12c, f, i). Martensitic-bainitic mixture is dominant after cooling the specimens at a rate of 2 and $1{ }^{\circ} \mathrm{C} \mathrm{s}^{-1}$, what is confirmed by previous results of dilatometric examinations. Apart from laths of martensite and bainite, large oval grains of ferrite are visible. Their size and shape clearly indicate that it is ferrite which has not transformed during austenitizing of steel at the temperature of $1,100{ }^{\circ} \mathrm{C}$, what is consistent with calculations of phase composition of steel under conditions of thermodynamic equilibrium. The fraction of ferrite is small. This phase is clearly visible only after lowering the cooling rate to $0.5^{\circ} \mathrm{C} \mathrm{s}^{-1}$. Ferrite is present mainly at grain boundaries of prior austenite. The dominant phase after cooling with the lowest cooling rate is bainite. The effect of deformation is manifested by a considerable refinement of microstructure as compared to non-deformed samples. The most fine-grained microstructure was obtained after deformation of steel at the temperature of $900{ }^{\circ} \mathrm{C}$, i.e. below recrystallization temperature 

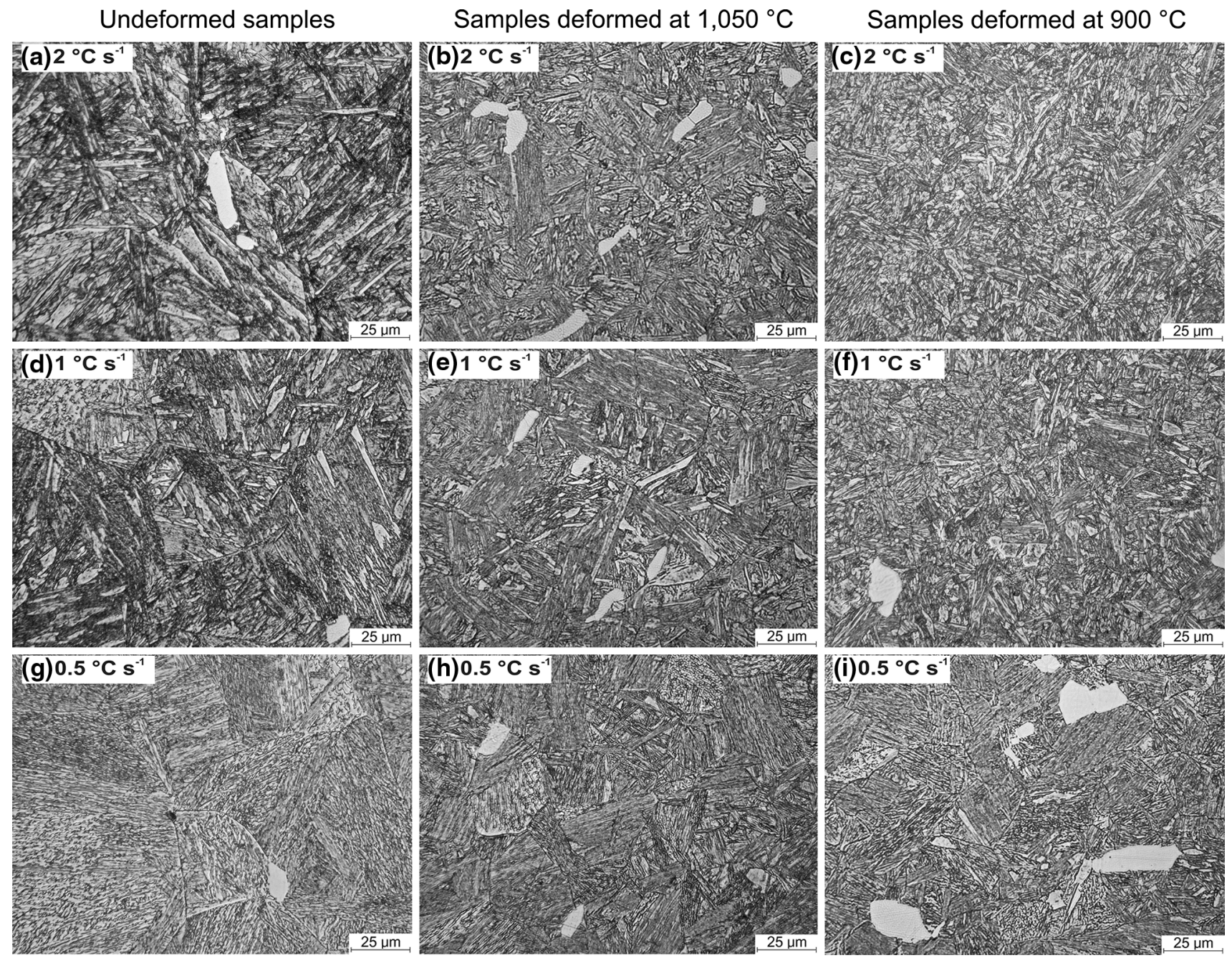

Fig. 12 Microstructures of undeformed samples $(\mathbf{a}, \mathbf{d}, \mathbf{g})$ and samples deformed at $1,050{ }^{\circ} \mathrm{C}(\mathbf{b}, \mathbf{e}, \mathbf{h})$ as well as at $900{ }^{\circ} \mathrm{C}(\mathbf{c}, \mathbf{f}, \mathbf{i})$ followed by their cooling within the rate range from 2 to $0.5^{\circ} \mathrm{C} \mathrm{s}^{-1}$

of $\gamma$ phase. The high density of lattice defects in austenite has a positive effect on both increasing the rate of bainite nucleation and growth as well as hampering of martensitic lamellas $[7,9,19]$.

The result of thermo-mechanical processing and isothermal holding of the specimens at $400{ }^{\circ} \mathrm{C}$ are microstructures presented in Fig. 13. First of all, multi-step deformation leads to a distinct refinement of all structural components as compared to the initial state (Fig. 4) and single strain at the temperature of 900 or $1050{ }^{\circ} \mathrm{C}$ (Fig. 12). A fraction of polygonal ferrite $(\alpha)$ is negligibly small, while the main structural constituent is bainite. However, there are fine, bright grains of $\gamma_{R}$ retained austenite at the boundaries of bainite sheaves (Fig. 13a). In addition to blocky grains with sizes of about $1 \mu \mathrm{m}$ between laths of bainitic ferrite $\left(\alpha_{\mathrm{B}}\right)$, there are also continuous or intermittent layers of $\gamma$ phase with diversified thickness. Such microstructure type is most often called a degenerate upper bainite $[18,19]$. Blocky grains larger than $1 \mu \mathrm{m}$ were partially transformed into martensite forming martensiticaustenitic (M-A) islands. Nevertheless, a fraction of martensite is significantly lower than under conditions of continuous cooling, and developed steel is susceptible to form microstructure of carbide-free bainite with high amount of retained austenite.

The volume fraction of retained austenite determined by XRD reaches $17.5 \%$ (Table 1). It is higher when compared to the samples in the initial state due to carbon partitioning from bainitic ferrite into residual austenite. The final grain refinement favours the stabilization of retained austenite too [19]. The thermal stabilization of the high volume fraction of retained austenite means that increased concentration of $\mathrm{Al}$ advantageously prevents precipitation of carbides during the isothermal bainitic transformation step. The obtained results are in good agreement with earlier literature data showing that $\mathrm{Al}$ is the 

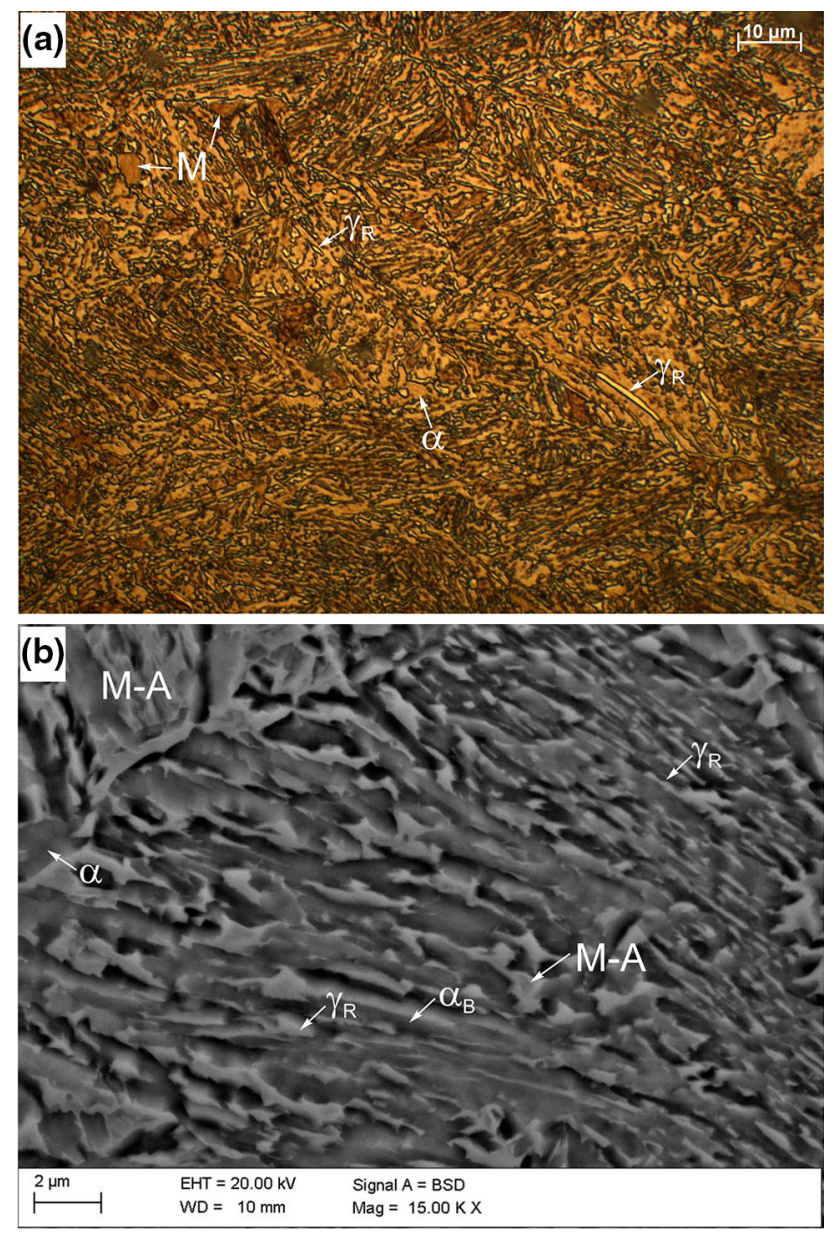

Fig. 13 Fine-grained degenerate upper bainite (a) containing interlath retained austenite, blocky-type $\gamma$ grains and martensite-austenite particles $(\mathbf{b}) ; \alpha$ polygonal ferrite, $\alpha_{\mathrm{B}}$ bainitic ferrite, $\gamma_{\mathrm{R}}$ retained austenite, $M-A$, martensite-austenite constituents

efficient protection against carbide precipitation at temperatures below $450{ }^{\circ} \mathrm{C}[1-3,18,25]$.

\section{Conclusions}

Investigated steel with increased concentration of $\mathrm{Mn}$ and $\mathrm{Al}$ is susceptible to form microstructure of carbide-free bainite with a high fraction of retained austenite. Determination of temperature range of individual phase transitions is complex. The identification of ferritic and bainitic transformation is possible only by differential dilatometric curve analysis. Correct identification of structural constituents requires a comprehensive combination of dilatometric and microstructural studies. It was found that martensite is dominant under conditions of continuous cooling and the fraction of bainite increases along with the decreasing cooling rate. Isothermal holding of steel at the temperature of $400{ }^{\circ} \mathrm{C}$ results in the stabilization of about $17 \%$ of interlath retained austenite. Grain refinement caused by plastic deformation of steel in the $\gamma$ range is an additional factor increasing the stability of retained austenite.

Acknowledgements The work was partially supported by the Polish Ministry of Science and Higher Education in a period of 2010-2012 in the framework of project No. N N508 590039.

Open Access This article is distributed under the terms of the Creative Commons Attribution License which permits any use, distribution, and reproduction in any medium, provided the original author(s) and the source are credited.

\section{References}

1. De Ardo AJ, Garcia JE, Hua M, Garcia CI. A new frontier in microalloying: advanced high strength, coated sheet steels. Mater Sci Forum. 2005;500-501:27-38.

2. Jung J, Lee SJ, Kim S, De Cooman BC. Effect of Ti additions on micro-alloyed Nb TRIP steel. Steel Res Int. 2011;82:857-65.

3. Bleck W, Phiu-On K. Microalloying of cold-formable multi phase steel grades. Mater Sci Forum. 2005;500-501:97-112.

4. Węglowski M, Kwieciński K, Krasnowski K, Jachym R. Characteristics of Nd:YAG laser welded joints of dual phase steel. Arch Civ Mech Eng. 2009;9:85-97.

5. Gronostajski Z, Niechajowicz A, Polak S. Prospects for the use of new-generation steels of the AHSS type for collision energy absorbing components. Arch Metall Mater. 2010;55:221-30.

6. Wiewiórowska S. Determination of content of retained austenite in steels with TRIP effect deformed at different strain rates. Steel Res Int. 2010;81:262-5.

7. Majta J, Muszka K. Mechanical properties of ultrafine-grained HSLA and and Ti-IF steels. Mater Sci Eng A. 2007;464:186-91.

8. Gibbs PJ, De Moor E, Merwin MJ, Clausen B, Speer JG, Matlock DK. Austenite stability effects on tensile behavior of manganeseenriched-austenite transformation-induced plasticity steel. Metall Mater Trans. 2011;42A:3691-702.

9. Grajcar A, Kuziak R, Zalecki W. Third generation of AHSS with increased fraction of retained austenite for the automotive industry. Arch Civ Mech Eng. 2012;12:334-41.

10. Grajcar A, Lesz S. Influence of $\mathrm{Nb}$ microaddition on a microstructure of low-alloyed steels with increased manganese content. Mater Sci Forum. 2012;706-709:2124-9.

11. Gazda AJ. Analysis of decomposition processes of ausferrite in copper-nickel austempered ductile iron. J Therm Anal Calorim. 2010;102:923-30.

12. Grajcar A, Kuziak R. Dynamic recrystallization behavior and softening kinetics in $3 \mathrm{Mn}-1.5 \mathrm{Al}$ TRIP steels. Adv Mater Res. 2011;287-290:330-3.

13. Smalc-Koziorowska J, Jezierska E, Świątnicki W. Identification of phases in alloy steels after quenching and after isothermal quenching. Solid State Phenom. 2012;186:301-4.

14. Kokosza A, Pacyna J. Mechanical stability of retained austenite in unalloyed structural steels of various carbon content. Arch Metall Mater. 2010;55:1001-6.

15. Zhao L, Top KA, Rolin V, Sietsma J, Mertens A, Jacques PJ, Van der Zwaag S. Quantitative dilatometric analysis of intercritical annealing in a low-silicon TRIP steel. J Mater Sci. 2002;37:1585-91.

16. Gojic M, Suceska M, Rajic M. Thermal analysis of low-alloy $\mathrm{Cr}$ Mo steel. J Therm Anal Calorim. 2004;75:947-56.

17. Yang JR, Bhadeshia HKDH. Continuous heating transformation of bainite to austenite. Mater Sci Eng. 1991;131A:99-113. 
18. Zajac S, Schwinn V, Tacke KH. Characterisation and quantification of complex bainitic microstructures in high and ultra-high strength linepipe steels. Mater Sci Forum. 2005;500-501:387-94.

19. Bhadeshia HKDH. Bainite in steels. Cambridge: The Institute of Materials. The University Press; 1992.

20. Caballero FG, Chao J, Cornide J, Garcia-Mateo C, Santofimia MJ, Capdevila C. Toughness deterioration in advanced high strength bainitic steels. Mater Sci Eng A. 2009;525:87-95.

21. Tsukatani I, Hashimoto S, Inoue T. Effects of silicon and manganese addition on mechanical properties of high-strength hotrolled sheet steel containing retained austenite. ISIJ Int. 1991;31:992-1000.

22. Caballero FG, Garcia-Mateo C, Garcia de Andres C. Dilatometric study of reaustenitisation of high silicon bainitic steels: Decomposition of retained austenite. Mater Trans. 2005;46:581-6.
23. Keul C, Wirths V, Bleck W. New bainitic steels for forgings. Arch Civ Mech Eng. 2012;12:119-25.

24. Standard practice for quantitative measurement and reporting of hypoeutectoid carbon and low-alloy steel phase transformations. ASTM Committee on Steel, Stainless Steel and Related Alloys. 2004.

25. Saunders N, Guo Z, Li X, Miodownik AP, Schillé JP. Using JMatPro to model materials properties and behavior. JOM. 2003;55:60-5.

26. De Cooman BC. Structure-properties relationship in TRIP steels containing carbide-free bainite. Curr Opin Solid State Mater Sci. 2004;8:285-303.

27. Garcia de Andres C, Caballero FG, Capdevila C, Alvarez LF. Application of dilatometric analysis to the study of solid-solid phase transformations in steels. Mater Charact. 2002;48:101-11. 